\title{
Differential expression of skeletal muscle genes following administration of clenbuterol to exercised horses
}

\author{
Heather K. Knych ${ }^{1,2^{*}}$, Linda M. Harrison ${ }^{3}$, Stacy J. Steinmetz ${ }^{1}$, Nadira Chouicha ${ }^{1}$ and Phil H. Kass ${ }^{4}$
}

\begin{abstract}
Background: Clenbuterol, a beta2-adrenergic receptor agonist, is used therapeutically to treat respiratory conditions in the horse. However, by virtue of its mechanism of action it has been suggested that clenbuterol may also have repartitioning affects in horses and as such the potential to affect performance. Clenbuterol decreases the percent fat and increases fat-free mass following high dose administration in combination with intense exercise in horses. In the current study, microarray analysis and real-time PCR were used to study the temporal effects of low and high dose chronic clenbuterol administration on differential gene expression of several skeletal muscle myosin heavy chains, genes involved in lipid metabolism and the $\beta 2$-adrenergic receptor. The effect of clenbuterol administration on differential gene expression has not been previously reported in the horse, therefore the primary objective of the current study was to describe clenbuterol-induced temporal changes in gene expression following chronic oral administration of clenbuterol at both high and low doses.

Results: Steady state clenbuterol concentrations were achieved at approximately $50 \mathrm{~h}$ post administration of the first dose for the low dose regimen and at approximately 18-19 days (10 days post administration of $3.2 \mu \mathrm{g} / \mathrm{kg}$ ) for the escalating dosing regimen. Following chronic administration of the low dose $(0.8 \mu \mathrm{g} / \mathrm{kg} \mathrm{BID})$ of clenbuterol, a total of 114 genes were differentially expressed, however, none of these changes were found to be significant following FDR adjustment of the $p$-values. A total of 7,093 genes were differentially expressed with 3,623 genes up regulated and 3,470 genes down regulated following chronic high dose administration. Of the genes selected for further study by real-time PCR, down-regulation of genes encoding myosin heavy chains 2 and 7, steroyl CoA desaturase and the $\beta 2$-adrenergic receptor were noted. For most genes, expression levels returned towards baseline levels following cessation of drug administration.

Conclusion: This study showed no evidence of modified gene expression following chronic low dose administration of clenbuterol to horses. However, following chronic administration of high doses of clenbuterol alterations were noted in transcripts encoding various myosin heavy chains, lipid metabolizing enzymes and the $\beta 2$-adrenergic receptor.
\end{abstract}

Keywords: Horse, Clenbuterol, Gene expression, TLDA, Microarray, $\beta 2$ agonist

\footnotetext{
* Correspondence: hkknych@ucdavis.edu

${ }^{1}$ K.L. Maddy Equine Analytical Chemistry Laboratory, School of Veterinary

Medicine, University of California, Davis, USA

${ }^{2}$ Department of Veterinary Molecular Biosciences, School of Veterinary

Medicine, University of California, Davis, USA

Full list of author information is available at the end of the article
} 


\section{Background}

Clenbuterol is a $\beta 2$-adrenergic receptor agonist that is labeled for use in the management of horses affected with airway obstruction. Clenbuterol, a moderately selective $\beta 2$-adrenergic receptor agonist, causes relaxation of airway smooth muscle by binding to the receptor and activating adenylyl cyclase. Activation of adenylyl cyclase leads to an increase in intracellular concentrations of cyclic adenosine monophosphate (cAMP) and ultimately activation of protein kinase A (PKA). In the airways this inhibits smooth muscle contraction by opening $\mathrm{K}^{+}$channels and down-regulating myosin light chain kinase activity [1].

$\beta 2$-adrenergic agonists are also known to promote lipolysis and increase muscle mass in many species [2-8]. This repartitioning effect and improvement in muscle growth efficiency has led to the addition of $\beta 2$-adrenergic agonists such as ractopamine and zilpaterol to feed products for production animals. While not approved for use as a growth-promoting agent, by virtue of its mechanism of action, clenbuterol when administered at high doses has been shown to have similar repartitioning effects in many species [2, 4-7]. Since clenbuterol is an approved therapeutic medication that is commonly used in racehorses, regulators have expressed concern regarding its potential to alter body composition in such a way as to affect performance. Supporting this concern are reports of decreases in the percent fat and increases in fat-free mass following high dose clenbuterol administration $(2.4 \mu \mathrm{g} / \mathrm{kg}$ BID) in horses when combined with intense exercise [5]. However, it should be noted that although changes in body mass have been documented in many species, performance is not necessarily improved and in some cases may be hindered $[4,9,10]$.

Increases in myofibrillar and structural proteins following clenbuterol administration have been well documented for several years [2-8]. More recently investigators have used gene expression analysis techniques including DNA microarray and qRT-PCR to elucidate the underlying mechanism for these changes [11, 12]. To date the molecular effects of clenbuterol administration on gene expression have been described in production animals and laboratory animal species [11, 12]. Spurlock and colleagues [11] demonstrated changes in the mRNA abundance of multiple genes associated with myogenic differentiation in mice following clenbuterol administration. Increases in expression levels of lipid metabolism related genes were demonstrated in pigs following clenbuterol administration [12]. Investigators speculated that one of these genes, apoR, might be critical in reducing fat accumulation [12].

While the effect of high dose clenbuterol on skeletal muscle fiber thickness in the horse has been assessed [6], there are no studies assessing the effects of clenbuterol at the molecular level in this species. Therefore, in the current study we chose to use DNA technology to assess the changes in skeletal muscle gene expression following high dose administration of clenbuterol to horses. Furthermore, studies describing muscle hypertrophy in horses have utilized high doses of the compound [5, 6] and although clenbuterol is labeled for use at doses as high as $3.2 \mu \mathrm{g} / \mathrm{kg}$ twice a day (BID), a more common therapeutic dosing regimen in performance horses in the United States is chronic low dose $(0.8 \mu \mathrm{g} / \mathrm{kg}, \mathrm{BID})$ administration. Therefore, the primary objective of the current study was to describe clenbuterolinduced temporal changes in gene expression following chronic oral administration of clenbuterol at both high and low doses. We hypothesized that clenbuterol would affect skeletal muscle gene expression (increased or decreased depending on the gene), relative to baseline levels, in the horse in a dose dependent manner.

\section{Methods}

Animals, clenbuterol treatment and sampling

Twenty-eight healthy, exercised adult Thoroughbred horses (11 mares and 17 geldings; weight range of $470.7 \pm 25.0 \mathrm{~kg}$; age range of 2-6 years) were studied. Horses used in this study were a combination of University and client owned horses. This study was approved by the Institutional Animal Care and Use Committee (University and client owned horses) and the Clinical Trials Committee of the University of California, Davis (client owned horses). For client owned horses, written consent was obtained for participation in the study. Prior to and throughout the course of the study, horses were exercised five days a week. The general exercise protocol was meant to simulate the strenuous exercise of race training. The exercise regimen for these horses consists of three days per week on an Equineciser (Centaur Horse Walkers Inc, Mira Loma, CA, USA) (5 min at walk; 30 min trot; 5 min walk) and two days per week on a high speed treadmill (Mustang 2200, Graber AG, Switzerland; Day 1: 5 min @1.6 m/s; 5 min @ $4 \mathrm{~m} / \mathrm{s} ; 5 \mathrm{~min} @ 7 \mathrm{~m} / \mathrm{s} ; 5 \mathrm{~min} @ 1.6 \mathrm{~m} / \mathrm{s}$ all at $6 \%$ incline. Day 2: 3 min @ $1.6 \mathrm{~m} / \mathrm{s} ; 4 \mathrm{~min} @ 4.0 \mathrm{~m} / \mathrm{s} ; 2 \mathrm{~min} @ 7.0 \mathrm{~m} / \mathrm{s}$; $2 \mathrm{~min} @ 11.0 \mathrm{~m} / \mathrm{s}$ and $5 \mathrm{~min} @ 1.6 \mathrm{~m} / \mathrm{s}$ all at $3 \%$ incline). All horses were subject to regular fitness testing, including weekly heart rate measurements and calculation of $V_{200}$ (running velocity that elicited a heart rate $200 \mathrm{bpm}$ ) and monthly measurements of end run plasma lactate concentrations, as a means by which to ensure that the fitness level of the horses used in this study were as comparable as possible to the average racehorse.

Prior to commencement of the study, all horses were determined healthy and free of cardiovascular diseases by physical examination, complete blood count and a serum biochemistry panel that included aspartate aminotransferase, creatinine phosphokinase, alkaline phosphatase, total 
bilirubin, sorbital dehydrogenase, blood urea nitrogen and creatinine. Horses did not receive any other medications for at least two weeks prior to conducting this study.

Twenty-two of the horses received $0.8 \mu \mathrm{g} / \mathrm{kg}$ clenbuterol (Ventipulmin ${ }^{\circ}$, Boehringer Ingelheim Vetmedica Inc, St Joseph, MO) PO BID for 30 days and an additional 6 horses received the escalating dosing protocol as described on the manufacturer label for non-responders $(0.8 \mu \mathrm{g} / \mathrm{kg}, \mathrm{BID} \times 3$ days; $1.6 \mu \mathrm{g} / \mathrm{kg}, \mathrm{BID} \times 3$ days; $2.4 \mu \mathrm{g} / \mathrm{kg}$, BID $\times 3$ days; $3.2 \mu \mathrm{g} / \mathrm{kg}$, BID for 21 days).

Blood samples were collected at time 0 and at 15, 30, and $45 \mathrm{~min}$, and $1,1.5,2,2.5,3,3.5,4,5,6,8$ and $12 \mathrm{~h}$ post administration of the first dose and last dose and $18,24,36,48,60,72,84,96,108$ and $120 \mathrm{~h}$ post administration of the last dose. Additionally blood samples were collected every $12 \mathrm{~h}$ (immediately prior to administration of each dose (trough concentrations)) throughout the 30-day dosing period. Blood samples were collected by direct venipuncture into EDTA blood tubes (Kendall/ Tyco Healthcare, Mansfield MA) and were centrifuged at $3000 \times \mathrm{g}$ for $10 \mathrm{~min}$. Plasma was immediately transferred into storage cryovials (Phenix Research Products, Chandler, $\mathrm{NC}$ ) and stored at $-20{ }^{\circ} \mathrm{C}$ until analysis. Drug concentrations were measured by Liquid Chromatography tandem Mass Spectrometry as described previously [13].

Muscle biopsy samples were collected one day prior to administration of the first dose of clenbuterol. Additional samples were collected at $48 \mathrm{~h}$ and on days 7,14 , and 28 post administration of the first dose. A final sample was collected one-week post administration of the final dose (35 days post administration of the first dose). Muscle biopsies were collected at the same time on each sampling occasion which was approximately $3-4 \mathrm{~h}$ post feeding. Horses were not exercised on the day that muscle biopsy samples were collected. For sample collection, horses were sedated with a combination of xylazine (Lloyd Inc, Shenandoah, IA) and butorphanol (Zoetis, Florham Park, NJ). Lidocaine (Aspen Veterinary Resources Ltd, Liberty MO) was administered subcutaneously over the gluteus muscle. A small area over the superficial gluteal muscle was aseptically prepped and a Bergstrom biopsy needle (Dixons Surgical Instruments, Wickford, Essex) used to collect a small sample (approximately $1 \mathrm{~g}$ of tissue). The tissue was transferred to a cryovial containing RNAlater (Qiagen Inc, Valencia, $\mathrm{CA}$ ) and stored at $-20^{\circ} \mathrm{C}$ until processed.

\section{RNA extraction and quality assessment}

Muscle biopsy samples were placed in $600 \mu \mathrm{l}$ of lysis buffer, contaning 2- $\beta$ - mercaptoethanol (Qiagen Inc, Valencia, CA). The tissue sample was then transferred to MagNa Green Beads tubes (Roche Diagnostics, Mannhein, Germany). Homogenization was performed using a MagNaLyse (Roche Diagnostics, Mannhein, Germany) at
$6000 \mathrm{rpm}$ for $30 \mathrm{~s}$ followed by a $1.0 \mathrm{~min}$ cool down period. Homogenization intervals were continued until pieces of muscle were no longer visible ( $\leq 3$ times). Total RNA was purified using an miRNeasy Mini kit (RNeasy Mini, Qiagen Inc, Valencia, CA) and following the manufacturer's instructions. Total RNA integrity was assessed using the Experion Automated Electrophoresis System (Bio-rad, Hercules, CA). Only RNA samples with RIN $\geq 8$ and 260/ 280 ratios between 1.7 and 2.1 were used $[14,15]$.

\section{Microarray analysis}

Equine specific microarrays (EquGene-1.0-st; Affymetrix, Santa Clara, CA), containing 504,603 probes representing 30,559 well-characterized genes were used.

To reduce biological noise as a result of genetic variability, each horse (5 horses for low dose administration and 4 horses for the escalating dosing regimen) was analyzed separately and served as their own control for comparison of baseline samples to day 14 (low dose administration) or day 28 (escalating dose regimen). Five biological replicates per time point were tested. Purified total RNA $(5 \mu \mathrm{g})$ was used for cDNA synthesis in accordance with the Ambion ${ }^{\circ}$ WT Expression assay kit (Affymetrix, Santa Clara, CA) manufacturer's protocol. In vitro transcription was used to incorporate biotin labels using the GeneChip WT Terminal Labeling system (Affymetrix, Santa Clara, CA) and samples hybridized to the Equine microarray. Arrays were washed and stained on a Fluidics Station 450 (Affymetrix, Santa Clara, CA) and scanned on a GeneChip Scanner 3000 (Affymetrix, Santa Clara, CA) in accordance with manufacturer's protocols.

The microarrays were evaluated for differential gene expression using Transcriptome Analysis Console (TAC) and for hybridization quality control using Expression Console Software (Affymetrix, Santa Clara, CA). In brief, a total of five Cell Intensity Files were generated per time point, uploaded and normalized under the following conditions: PM (perfect match)-only as a PM intensity adjustment and the Robust Multichip Analysis (RMA) quantification method. For evaluation of the assays performance the number of differentially expressed (DE) genes detected between baseline and day 14 (low dose administration) or day 28 (escalating dose regimen) were assessed. Based on the TAC software user's manual, genes with mean transformed ratios significantly less than -2 and larger than +2 were considered significantly regulated. Significant DE genes were selected by filtering the genes using an ANOVA ( $p$ value $<0.05$ ). A Pearson's correlation coefficient was used to calculate linear dependence between time point and baseline samples to evaluate the correlation coefficient, where 1 was a positive correlation and 0 was no correlation. For each probeset, expression at day 14 (low dose administration) or 
day 28 (escalating dose regimen) was compared to expression at baseline in the same horse using a paired $t$-test. Fold changes and their confidence intervals were calculated by exponentiating (base 2) the mean withinhorse difference in expression for each gene and the associated $\mathrm{t}$ confidence intervals. $P$-values were adjusted for multiple testing using the False Discovery Rate (FDR) method of Benjamini and Hochberg [16]. Analyses were conducted using the statistical software environment R, version 3.0.2 (R Core Team, 2013). Gene Ontology biological process of differently expressed genes of interest was performed using the most recent Database for Annotation, Visualization and Integrated Discovery (DAVID) 6.8 Beta (https://david-d.ncifcrf.gov/) with the Entrez Gene ID as the primary identifier and Equus Caballus as the species.

\section{Quantification of mRNAs using Taqman low density arrays (TLDA)}

Genes that showed significant changes in expression (greatest fold change and statistical significance) following microarray analysis as well as those that have previously been reported to be affected by clenbuterol administration, were chosen as candidate genes for further study. Microarray data were validated by measuring the levels of specific mRNA in muscle biopsy samples at each time point post clenbuterol administration vs. baseline via Taqman Low Density Arrays (TLDA; Affymetrix, Santa Clara, CA) which are pre-loaded 384 well RT-PCR microfluidic cards.

RNA was diluted to a concentration of $2 \mathrm{ng} / \mu \mathrm{l}$ for cDNA conversion using the QuantiTect Reverse Transcription Kit (Qiagen Inc., Valencia, CA). cDNA was then combined with Taqman Universal Mastermix (Affymetrix, Santa Clara, CA) at a final concentration of $2 \mathrm{X}$ and then 100ul of each sample loaded onto the TLDA card.

Primers for candidate genes were designed and manufactured by Life Technologies (Affymetrix, Santa Clara, CA). Reference or "housekeeping" genes were used to evaluate the effect of RNA integrity on the array and qRT-PCR performance. Based on stability across all samples studied (TaqMan Protocol [17]) equine beta 2 microglobulin $(\beta 2 M)$ was used as the endogenous control gene to normalize the qRT-PCR data while human $18 \mathrm{~s}$ (hs18s) was used as an internal manufacturing control. Each sample was run in quadruplicate with 10 candidate genes per card. The TLDA cards were then run on a QuantStudio $^{\text {Tw }} 12$ K Flex Software v1.2.2 (Affymetrix, Santa Clara, CA). Analysis was performed using ExpressionSuite Software 1.0.3 using Singleplex analysis (Affymetrix, Santa Clara, CA).

Statistical analyses using commercially available software (Stata/IC 13.1, StataCorp LP, College Station, TX) were performed to assess significant differences in expression (fold change) between baseline and each time point as well as between the different time points post clenbuterol treatment. Data was analyzed using a mixed effects analysis of variance, with the horse treated as a random effect, and with time as fixed effects. Post-hoc comparisons were performed with a Bonferonni multiplecomparison adjustment to preserve a nominal significance level of 0.05 .

\section{Results \\ Plasma clenbuterol concentrations}

The average clenbuterol plasma concentration over time-curves following chronic low dose and escalating dose administrations are depicted in Fig. 1a, b, respectively. Clenbuterol plasma concentrations were below detectable levels by day 7 post administration of the final dose in all 22 horses studied at the low dose and below the LOQ of the assay by day 7 in $5 / 6$ horses receiving the escalating dosing protocol. The terminal elimination half-life was $10.4 \pm 4.4 \mathrm{~h}$ (mean $\pm \mathrm{SD}$ ) following chronic low dose administration and $46.2 \pm 8.37 \mathrm{~h}$ (mean $\pm \mathrm{SD}$ ) following administration of the last dose $(3.2 \mu \mathrm{g} / \mathrm{kg})$ of the escalating dosing protocol. Steady state concentrations were achieved at approximately $50 \mathrm{~h}$ post administration of the first dose for the low dose regimen and at approximately $18-19$ days (10 days post administration of $3.2 \mu \mathrm{g} / \mathrm{kg}$ ) for the escalating dosing regimen.

\section{CDNA microarray analysis}

Equine specific microarrays containing expression profiling of 25,923 well-characterized genes were utilized. The data has been deposited in the NCBI's Gene Expression Omnibus (GEO) [18] and are accessible through GEO series accession number GSE79559. Baseline samples collected the day prior to drug administration were compared to those collected on day 14 (low dose administration) or day 28 (escalating dose regimen). Following chronic administration of the low dose $(0.8 \mu \mathrm{g} / \mathrm{kg}$ BID $)$ of clenbuterol, a total of 114 genes were $\mathrm{DE}$, however, none of these changes were found to be significant following FDR adjustment of the $p$-values. The volcano plot of differentially abundant transcripts generated from microarray analysis is depicted in Fig. 2a.

Following administration of the escalating dosing protocol increases in expression levels of a number of genes were noted. The volcano plot of differentially abundant transcripts generated from microarray analysis is depicted in Fig. 2b. A total of 7,093 genes were $\mathrm{DE}$ with 3,623 genes up regulated and 3,470 genes down regulated. Differentially expressed genes were divided into groups according to their Gene Ontology Biological Process descriptions (Table 1). A total of 537 unique genes were identified and classified. The largest number of genes were regulation of cellular process related (247). Forty-three genes were actin- 

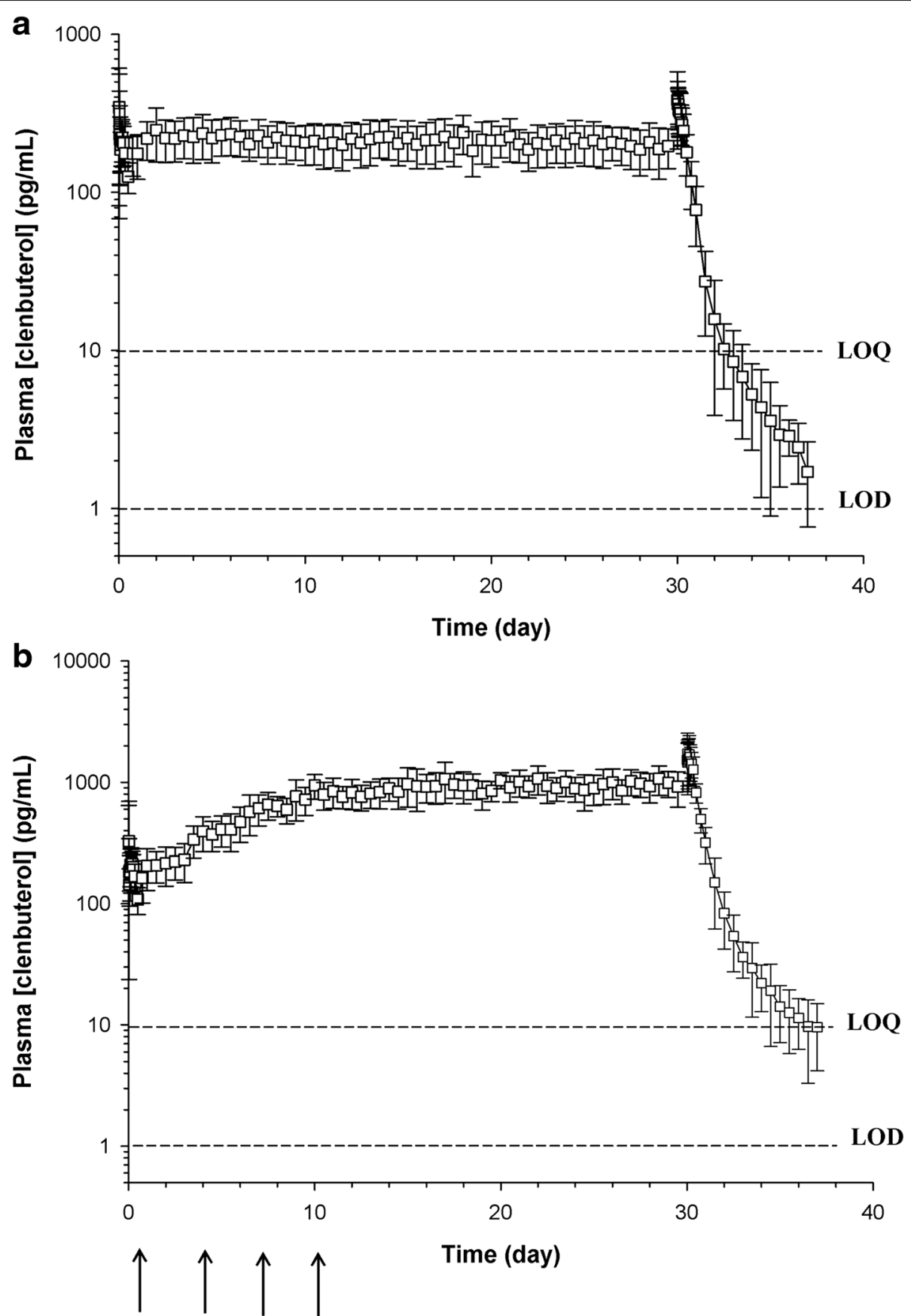

Fig. 1 Mean \pm SD plasma clenbuterol concentrations vs time following chronic (a) low dose and (b) high dose administration of (a) $0.8 \mu \mathrm{g} / \mathrm{kg}$ Ventipulmin ${ }^{\circledR}$ BID for 30 days to 22 racing fit Thoroughbred horses and (b) Ventipulmin ${ }^{\otimes}(0.8 \mu \mathrm{g} / \mathrm{kg}$, BID for 3 days, $1.6 \mu \mathrm{g} / \mathrm{kg}$, BID for 3 days, $2.4 \mu \mathrm{g} / \mathrm{kg}$, BID for 3 days and $3.2 \mu \mathrm{g} / \mathrm{kg}$, BID for 21 days) to 6 racing fit Thoroughbred horses. Arrows indicate administration of a new dose

filament-based process related, 28 involved in muscle system processes and 10 related to striated muscle contraction.

Sixteen selected DE genes are listed in Table 2. Based on the results of the microarray analysis (greatest fold change and statistical significance) and previously reported effects of clenbuterol on skeletal muscle and lipid metabolism, 13 genes were selected for further analysis to quantitate the change in expression levels, relative to baseline, at several time points during the dosing period and following termination of clenbuterol administration. 
a

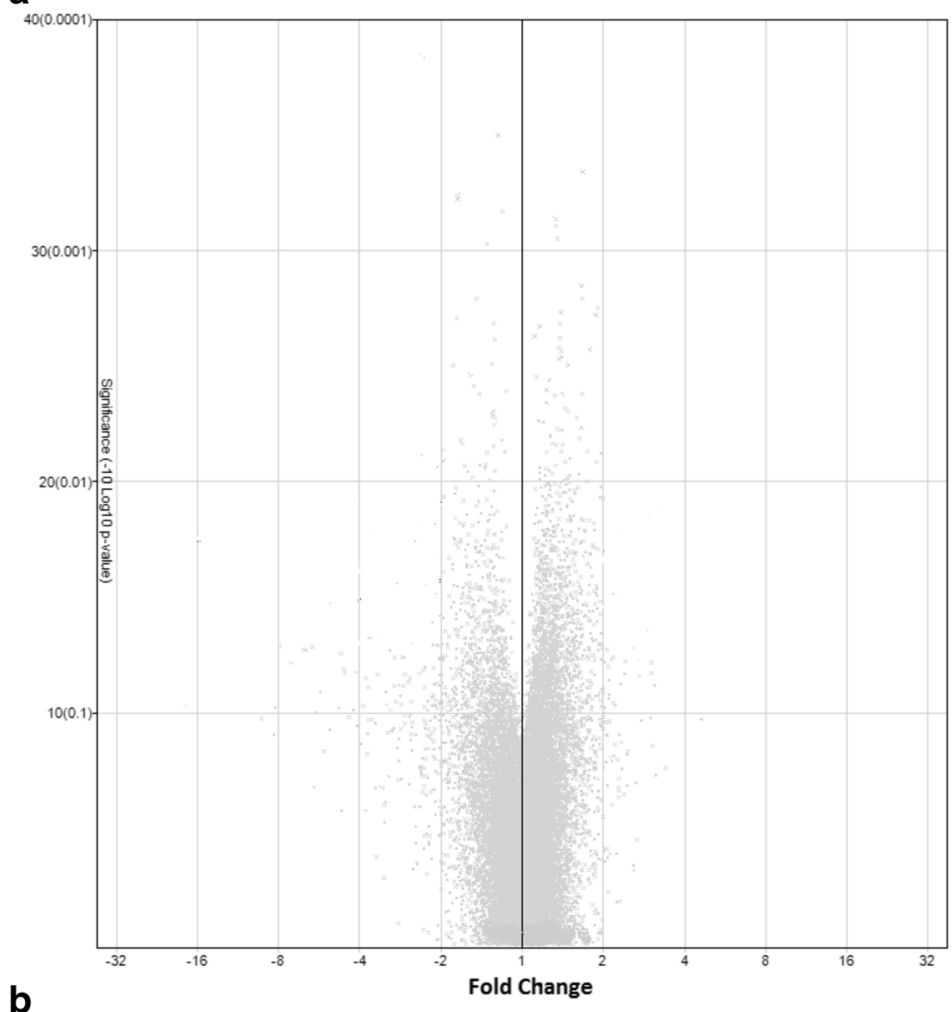

b

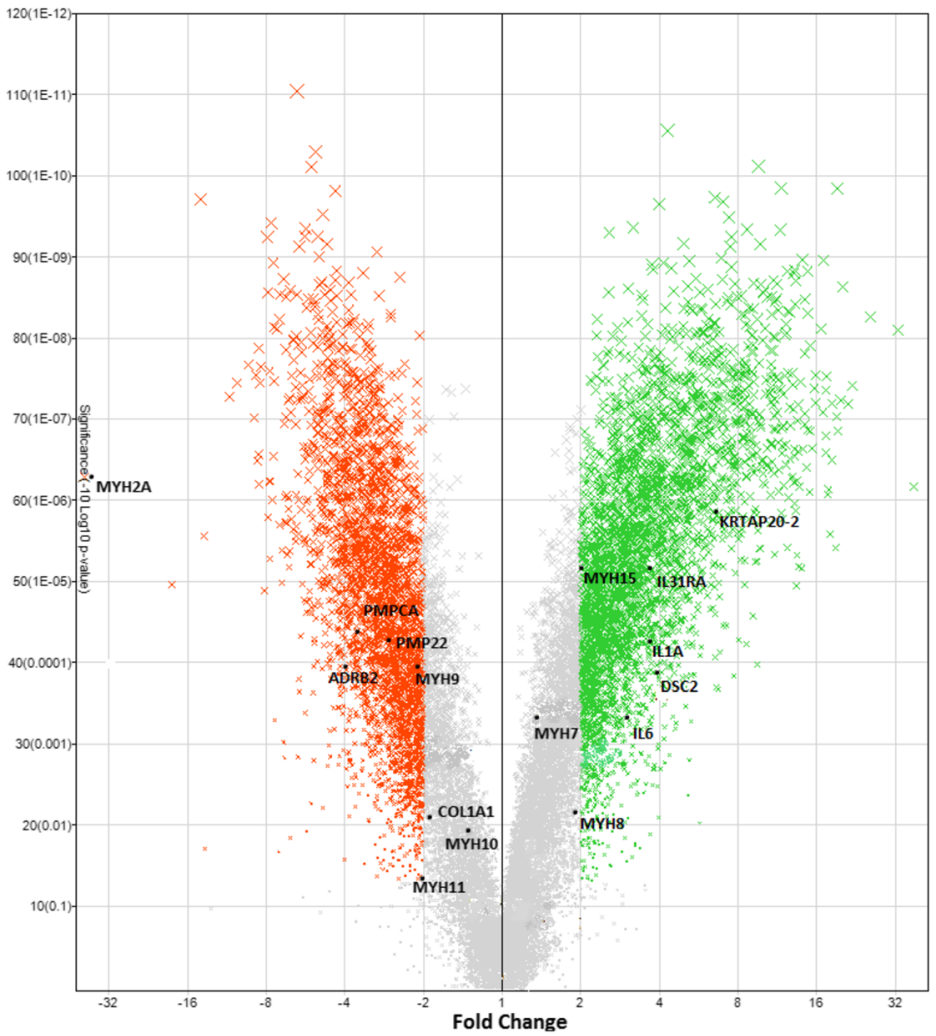

Fig. 2 (See legend on next page.) 
(See figure on previous page.)

Fig. 2 Volcano plot of differentially abundant transcripts at 2 weeks following oral administration of $0.8 \mu \mathrm{g} / \mathrm{kg}$ Ventipulmin ${ }^{\oplus}$ BID for 30 days to 22 racing fit Thoroughbred horses and (b) 4 weeks following oral administration of Ventipulmin ${ }^{\oplus}(0.8 \mu \mathrm{g} / \mathrm{kg}, \mathrm{BID}$ for 3 days, $1.6 \mu \mathrm{g} / \mathrm{kg}, \mathrm{BID}$ for 3 days, $2.4 \mu \mathrm{g} / \mathrm{kg}$, BID for 3 days and $3.2 \mu \mathrm{g} / \mathrm{kg}$, BID for 21 days) to 6 racing fit Thoroughbred horses. Red and green dots represent genes that are significantly down-regulated and up-regulated, respectively

\section{Quantification of mRNAs using Taqman low density arrays (TLDA)}

Genes selected for TLDA analysis included: $\beta 2$-adrenergic receptor $(\beta 2 R)$, myosin heavy chain $2(M Y H C 2 A)$, myosin heavy chain 7 (MYH7), myosin heavy chain 8 (MYH8), myosin heavy chain 15 (MYHC15), myosin light chain kinase $(M Y L K)$, muscle skeletal receptor tyrosine kinase (MUSK), collagen type 3A1 (COL3A1), collagen type 1A1 (COL1A1), collagen type 1A2 (COL1A2), matrix metalloproteinase 13 (MMP13), steroyl CoA desaturase (SCD) and lipoprotein lipase $(L P L)$. Expression levels, relative to baseline, at each time during and post clenbuterol administration for genes analyzed using TLDA are depicted in Fig. 3.

Of the 13 genes selected for TLDA analysis, 7 showed a similar significant change (up or down-regulation) in expression as that demonstrated on microarray analysis. While changes in expression were detected for the remaining 6 genes (MYH8, MYLK, MUSK, COL3A1, COL1A2, MMP13 and $L P L)$ these were not deemed statistically significant.

Table 1 Differentially expressed genes of interest $(p<0.05)$ categorized according to the Gene Ontology biological process terms

\begin{tabular}{ll}
\hline Gene ontology biological process category & Number of genes \\
\hline Regulation of cellular process & 247 \\
Localization & 177 \\
Proteolysis & 172 \\
Regulation of development & 125 \\
Death & 117 \\
Morphogenesis & 116 \\
Cell Adhesion & 99 \\
Biological Adhesion & 99 \\
Intracellular Transport & 95 \\
Homeostasis & 74 \\
Membrane Organization & 72 \\
Cell Differentiation & 71 \\
Cell Communication & 58 \\
Actin-Filament Based Process & 43 \\
Muscle System Process & 28 \\
Response Stimulus & 20 \\
Striated Muscle Contraction & 10 \\
\hline
\end{tabular}

A total of 537 unique gene identifiers were identified and classified in categories with a minimum of 6 members
$M Y H 2 A$ was significantly down-regulated, compared to baseline, on days 7, 14 and 28 post clenbuterol administration with transcript levels returning towards normal on day 35 (7 days post administration of the final dose). $M Y H 7$ was also down-regulated starting on day 7 and continuing through day 35 . On day 7 , transcript was significantly different from baseline and $48 \mathrm{~h}$ and subsequent samples were significantly different from day 7 levels. On day 7, MYH15 was significantly different from baseline and $48 \mathrm{~h}$ transcript levels and on days 14 and 28 , it was significantly different from day 7 . The only collagen gene affected following clenbuterol administration was COL1A2 on days 14 (significantly different from baseline transcript levels) and 28 (significantly different from day 14). Although not significant, SCD transcript levels first increased relative to baseline (48 h and day 7). Starting with the day 14 sample and continuing through the final time point (day 35), SCD transcripts were significantly down-regulated compared to baseline. The $\beta 2$ adrenergic receptor was up-regulated, although not significantly so at the first two time points ( $48 \mathrm{~h}$ and day 7). Significant down-regulation of the $\beta 2 R$ gene was noted on days 14 (compared to $48 \mathrm{~h}$ ), 28 (compared to baseline, $48 \mathrm{~h}$ and day 7 ) and 35 (compared to day 28).

\section{Discussion}

Clenbuterol administration has been associated with changes in body composition including alterations in lipid metabolism and changes in skeletal muscle fibers [2-8]. Numerous studies have shown that these drug-induced alterations are a result of changes at the molecular level, namely changes in mRNA expression $[11,12]$. Alterations in body composition, including a significant shift in the myosin heavy chain protein profile [6] and alterations in plasma leptin and adipopnectin concentrations [7] have been reported following clenbuterol administration to horses. However, to the best of the authors' knowledge, this is the first report to describe temporal alterations in mRNA expression following clenbuterol administration to horses, using 2 commonly used dosing regimens.

As a means of providing a global overview of genes affected by clenbuterol administration, microarray analysis, comparing mRNA levels prior to drug administration to the levels at 2 weeks (low dose administration) or 4 weeks (escalating dose regimen) post drug administration was used. No significant changes in gene expression were noted following administration of the chronic low dose protocol $(0.8 \mathrm{ug} / \mathrm{kg}$ BID $\times 30$ days $)$. Conversely, 
Table 2 Selected differentially expressed genes utilizing an equine specific microarray following administration of an escalating dosing regimen $(0.8 \mu \mathrm{g} / \mathrm{kg}, \mathrm{BID} \times 3$ days; $1.6 \mu \mathrm{g} / \mathrm{kg}, \mathrm{BID} \times 3$ days; $2.4 \mu \mathrm{g} / \mathrm{kg}, \mathrm{BID} \times 3$ days; $3.2 \mu \mathrm{g} / \mathrm{kg}$, BID for 21 days $)$ to 6 exercised Thoroughbred research horses. For microarray analysis, baseline (pre-dose) transcript levels were compared to transcript levels on day 28

\begin{tabular}{|c|c|c|c|}
\hline Gene symbol & Gene name & Fold change & $P$ value (FDR corrected) \\
\hline MYHZA & Myosin Heavy Chain 2A, skeletal muscle & -30.5 & $<0.001$ \\
\hline MYH7 & Myosin Heavy Chain 7, cardiac and skeletal & 1.39 & 0.002 \\
\hline MYH8 & Myosin Heavy Chain 8, skeletal muscle & 1.86 & 0.014 \\
\hline MYH9 & Myosin Heavy Chain 9, non-muscle & -2.60 & 0.001 \\
\hline MYH10 & Myosin Heavy Chain 10, non-muscle & -1.31 & 0.028 \\
\hline MYH11 & Myosin Heavy Chain 11, smooth muscle & -2.24 & 0.033 \\
\hline MYH15 & Myosin Heavy Chain 15 & 2.10 & $<0.001$ \\
\hline$A D R B 2$ & Adrenoreceptor, beta 2 & -4.0 & 0.001 \\
\hline COLIA1 & Collagen, type 1, alpha 1 & -1.8 & 0.019 \\
\hline IL1A & Interleukin 1, alpha & 3.42 & $<0.001$ \\
\hline IL6 & Interleukin 6 & 3.38 & 0.002 \\
\hline IL3TRA & Interleukin 31, receptor A & 2.77 & $<0.001$ \\
\hline DSC2 & Desmocollin 2 & 2.95 & 0.001 \\
\hline PMP22 & Peripheral myelin protein 22 & -2.5 & $<0.001$ \\
\hline$P M P C A$ & Peptidase alpha & -2.64 & $<0.001$ \\
\hline KRTAP20-2 & Keratin associate protein $20-2$ & 7.32 & $<0.001$ \\
\hline
\end{tabular}

following high dose chronic administration, significant changes were noted in genes coding for select myosin heavy chain isoforms, proteins involved in fatty acid metabolism and the $\beta 2$ adrenergic receptor. The remainder of this discussion pertains to the high dose (escalating dosing) regimen.

\section{Skeletal muscle fibers}

Myosins are actin-based motor proteins that function in the generation of mechanical force [19] and are responsible for producing contraction in muscle cells. There are a number of isoforms of myosin heavy chains and fiber type is dependent on the isoform that is present. Myosin heavy chains are encoded by a highly conserved multi-gene family and include isoforms such as $2 \mathrm{~A}, 2 \mathrm{~B}$ and 2X [19]. The $M Y H 2 B$ gene is not expressed in equine skeletal muscle [20]. Myosin heavy chain 7 is another member of the myosin family found primarily in cardiac but also in skeletal muscle [21] and encoded by the $M Y H 7$ gene.

Alterations in the skeletal muscle fiber profile have been described following administration of $\beta 2$ adrenergic agonists, including clenbuterol and ractopamine $[11,12,22,23]$. At the protein level, this most commonly involves a shift from the MYH1 to the MYH2A and $2 \mathrm{X}$ fiber type [24-26]. In the current study, there was not a significant change in either $M Y H 1$ or $M Y H 2 X$ gene expression on microarray analysis, therefore, these genes were not selected for further study. In a study similar to the currently reported one, ractopamine was administered to pigs, yielding similar results with respect to $M Y H 1$ expression [22]. An apparent lack of agreement between expression of $M Y H$ transcripts and protein isoforms has been described previously in horses and was attributed to the presence of hybrid fibers [27]. Additionally, other investigators have theorized that fibers that have more than one MYH protein and only one transcript could be a result of fibers converting to the type corresponding to the expressed transcript [28-30].

A decrease in MYH2A protein levels has been demonstrated in horses following administration of clenbuterol [6]. Similarly, in the current study, $M Y H 2 A$ gene expression was significantly down regulated (relative to baseline). This was first observed on day 7 and continued throughout the dosing period with maximum effects on expression occurring on 28. This was also the time at which steady state clenbuterol concentrations post the final dose escalation, were achieved, suggesting a dose dependent effect. $M Y H 2 A$ levels were not significantly different from baseline at the last time point tested, which was 5 days after termination of dosing, further supporting a dose dependent effect.

\section{Genes involved in lipid metabolism}

SCD is responsible for converting fatty acids into monounsaturated fatty acids in mammalian adipocytes [31]. Up-regulation of the $S C D$ gene in skeletal muscle has been associated with abnormal lipid partitioning and 


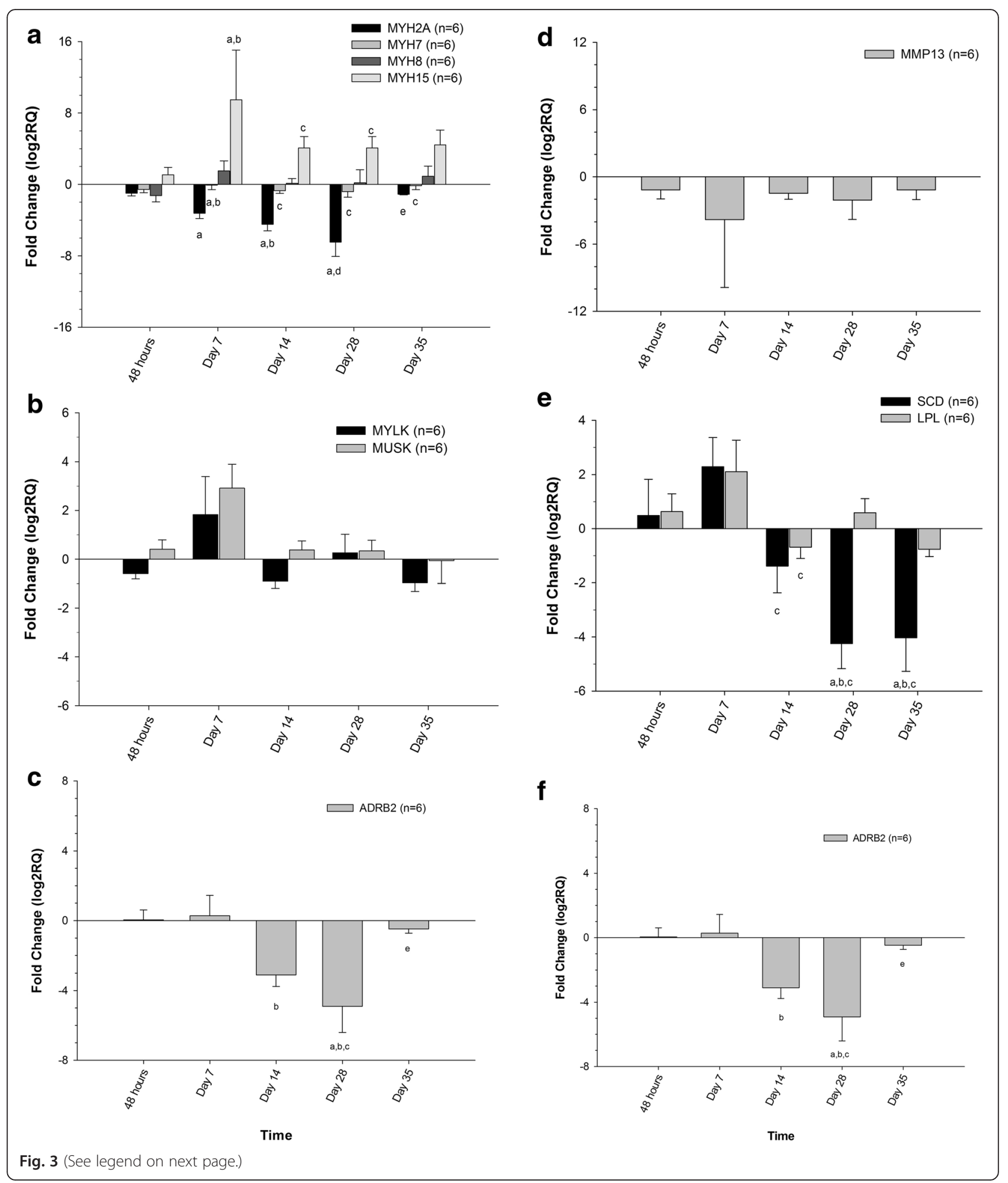


(See figure on previous page.)

Fig. 3 Mean relative expression (compared to baseline) of a myosin heavy chains (MYH2A, MYH7, MYH8, MYH15), b myosin light chain kinase (MYLK) and skeletal muscle receptor tyrosine kinase (MUSK), c collagen type 1A1 (COL1A1), collagen type 1A2 (COL1A2) and collagen type 3A1 (COL3A1), d matrix metalloproteinase 13 (MMP13), e steroyl CoA desaturase (SCD) and lipoprotein lipase ( $L P L)$ and $\mathbf{f} \beta 2$-adrenergic receptor ( $\beta 2 R)$ in skeletal muscle following oral administration of clenbuterol at the high dose protocol (Ventipulmin ${ }^{\oplus} 0.8 \mu \mathrm{gg} / \mathrm{kg}, \mathrm{BID}$ for 3 days, $1.6 \mu \mathrm{g} / \mathrm{kg}$, BID for 3 days, $2.4 \mu \mathrm{g} / \mathrm{kg}$, BID for 3 days and $3.2 \mu \mathrm{g} / \mathrm{kg}$, BID for 21 days) to 6 racing fit Thoroughbred horses. ${ }^{\text {a }}$ represents changes that are significantly different $(p<0.05)$ from baseline (pre-treatment), ${ }^{b}$ represents changes that are significantly different $(p<0.05)$ from 48 h, ${ }^{C}$ represents changes that are significantly different $(p<0.05)$ from day 7 , ${ }^{d}$ represents changes that are significantly different $(p<0.05)$ from day 14 , ${ }^{e}$ represents changes that are significantly different $(p<0.05)$ from day $28{ }^{f}$ represents changes that are significantly different $(p<0.05)$ from day 35

obesity in humans and lower levels of SCD with a leaner body type [32]. $\beta 2$ adrenergic agonists have demonstrated effects on lipid metabolism [12], including downregulation of $S C D$. This has been demonstrated in pigs following 4 weeks of treatment with ractopamine (25 mg/kg BID; [12]). In the current study, SCD mRNA expression decreased starting on day 14 and continued until 7 days post clenbuterol administration (day 35). This time course is highly suggestive of a dosedependent effect as no effects on SCD were observed following chronic low dose administration $(0.8 \mathrm{ug} / \mathrm{kg}$ BID $\times 30$ days). Furthermore, following administration of the escalating non-responder dosing regimen, significant effects were not observed until day 14, after significant drug accumulation had occurred.

\section{B2- adrenergic receptor}

Chronic administration of $\beta 2$-adrenergic agonists has been associated with down-regulation of the $\beta 2$-adrenergic receptor in humans [33] and horses [34]. In conjunction with this down-regulation, a number of investigators have noted a decrease in $\beta 2 R$ mRNA [34]. Decreased levels of $\beta 2 R$ mRNA has been reported in fast twitch muscle fibers in rats following clenbuterol administration [33, 35] and in pigs following long-term ractopamine administration [22]. In the current study, $\beta 2 R$ mRNA levels were unaffected following low dose clenbuterol administration, however, following administration of the escalating dosing protocol, mRNA levels decreased significantly by days 14 and 28. Abraham and colleagues [34] demonstrated a down-regulation of $\beta 2$-adrenergic receptors following chronic clenbuterol administration and theorized that this provided an explanation for variable sensitivity of horses with chronic obstructive pulmonary disease to $\beta 2$ adrenergic agonists as well as the development of tolerance with long term treatment. Similarly in the current study, decreased $\beta 2 R$ mRNA expression as a result of high dose chronic clenbuterol administration may lead to down-regulation of $\beta 2$-adrenergic receptors and offer an explanation for the decreased expression of $M Y H$, MYLK, MUSK, ACD and LPL. By day 35 (7 days post termination of drug administration), $\beta 2 R$ levels had returned towards baseline levels, presumably due to decreasing concentrations of clenbuterol.

\section{Conclusion}

In the current study, we describe changes in gene expression in skeletal muscle following chronic administration of clenbuterol to horses. Changes in gene expression were not noted following administration of therapeutic low doses, however, following chronic administration of high doses of clenbuterol alterations were noted in transcripts encoding various myosin heavy chains, lipid metabolizing enzymes and the $\beta 2 R$.

\section{Abbreviations}

$\beta 2 R, \beta 2$-adrenergic receptor; BID, Twice a day; CAMP, cyclic adenosine monophosphate; COL1A1, collagen type 1A1; COL1A2, collagen type 1A2; COL3A1, collagen type $3 A 1 ; D E$, differentially expressed; FDR, false discovery rate; GEO, gene expression omnibus; $L P L$, lipoprotein lipase (LPL); MMP13, matrix metalloproteinase 13; MUSK, muscle skeletal receptor tyrosine kinase; MYH7, myosin heavy chain 7; MYH8, myosin heavy chain 8; MYHC15, myosin heavy chain 15; MYHC2A, myosin heavy chain 2; MYLK, myosin light chain kinase; PKA; protein kinase A; RMA, robust multichip analysis; SCD, steroyl CoA desaturase; TLDA, taqman low density arrays

\section{Acknowledgements}

The authors would like to thank Haley Casbeer, Amy Young, Elizabeth Lee, Carley Corado and Vanessa Covarrubias for assistance and Ellen Jackson and Victory Rose Thoroughbreds for providing horses for this study. The authors would also like to thank Ryan R. Davis (UCDCCC Genomics Shared Resource, Department of Pathology and Laboratory Medicine) for his expert technical assistance for the microarray studies. The UC Davis Comprehensive Cancer Center Genomics Shared Resource is supported by Cancer Center Support Grant P30 CA093373 (R.W. de Vere White) from the NCl.

\section{Funding}

This study was funded with the first author's program funds.

\section{Availability of data and materials}

The dataset supporting the conclusions of this article is available in the NCBI's Gene Expression Omnibus (http://www.ncbi.nlm.nih.gov/geo/query/ acc.cgi?acc=GSE79559).

\section{Authors' contributions \\ HKK conceived of the study and participated in its design and coordination, carried out drug administration studies and sample collection, performed data analysis and drafted the manuscript and approved of the final manuscript. LMH participated in study design, carried out drug administration studies and sample collection, helped to draft the manuscript and approved of the final manuscript. SJS participated in study design, carried out drug administration studies and sample collection and approved the final manuscript. NC carried out microarray and TLDA analysis, participated in drafting the manuscript and final manuscript approval. PHK conducted the statistical analysis of TLDA results as well as assisting with drafting manuscript and final approval of the manuscript.}

\section{Competing interests}

The authors declare that they have no competing interests. 


\section{Consent for publication}

Not Applicable.

\section{Ethics approval and consent to participate}

Data was obtained and analyzed under approval of the Institutional Animal Care and Use Committee and the Clinical Trials Committee of the University of California, Davis. For client owned horses, written consent was obtained for participation in the study.

\section{Author details}

'K.L. Maddy Equine Analytical Chemistry Laboratory, School of Veterinary Medicine, University of California, Davis, USA. ${ }^{2}$ Department of Veterinary Molecular Biosciences, School of Veterinary Medicine, University of California, Davis, USA. ${ }^{3}$ Willow Oak Equine, Woodland, CA, USA. ${ }^{4}$ Department of Population Health and Reproduction, School of Veterinary Medicine, University of California, Davis, USA.

Received: 24 March 2016 Accepted: 18 July 2016

Published online: 09 August 2016

\section{References}

1. Robinson NE. Clenbuterol and the horse. AAEP Proc. 2000;42:229-33.

2. Emery PW, Rothwell NJ, Stock MJ, Winter PD. Chronic effects of beta 2-adrenergic agonists on body composition and protein synthesis in the rat. Biosci Rep. 1984:4:83-91.

3. Bergen WG, Johnson SE, Skaerlund DM, Babiker AS. Muscle protein metabolism in finishing pigs fed ractopamine. J Anim Sci. 1989:67:2255-62.

4. Eisemann $\mathrm{JH}$, Huntington $\mathrm{GB}$, Ferrell CL. Effects of dietary clenbuterol on metabolism of the hindquarters in steers. J Anim Sci. 1987:66:342-53.

5. Kearns CF, McKeever KH, Malinowski K, Struck MB, et al. Chronic administration of therapeutic levels of clenbuterol acts as a repartitioning agent. J Appl Physiol. 2001;91:2064-70.

6. Beekley MD, Ideus JM, Brechue WF, Kearns CF, et al. Chronic clenbuterol administration alters myosin heavy chain composition in Standardbred mares. Vet J. 2003;165:234-39.

7. Kearns CF, McKeever KH, Malinowski K. Changes in adipopnectin, leptin, and fat mass after clenbuterol treatment in horses. Med Sci Sports Exerc. 2006;38:262-7.

8. Johnson BJ. Mechanism of action of beta adrenergic agonists and potential residue issues. American Meat Association Reference Paper. 2014: 1-6.

9. Ingalls CP, Barnes PWS, Smith SB. Interaction between clenbuterol and run training: effects on exercise performance and MLC isoform content. J Appl Physiol. 1996;80:795-801.

10. Duncan ND, Williams DA, Lynch GS. Deleterious effects of chronic clenbutero treatment on endurance and sprint exercise performance in rats. Clin Sci (Lond). 2000;98:339-47.

11. Spurlock DM, McDaneld TG, Mclntyre LM. Changes in skeletal muscle gene expression following clenbuterol administration. BMC Genomics. 2006:7:320-35

12. Zhang J, He Q, Liu QY, Guo W, et al. Differential gene expression profile in pit adipose tissue treated with/without clenbuterol. BMC Genomics. 2007:8:433-45

13. Knych HK, Mitchell MM, Steinmetz SJ, McKemie DS. Detection, pharmacokinetics and cardiac effects following administration of clenbuterol to exercised horses. Equine Vet J. 2014:46:380-85.

14. Denisov, V, Strong, W, Walder M, Gingrich J, et al. Development and validation of RQI: an RNA quality indicator for the Experion automated electrophoresis system. Electrophoresis Technical Note 5761. 2008.

15. Fleige $S$, Walf $V$, Huch S, Prgomet $C$, et al. Comparison of relative mRNA quantification models and the impact of RNA integrity in quantitative real time RT-PCR. Biotechnol Lett. 2006;28:1601-13.

16. Benjamini $Y$, Hochberg Y. Controlling the false discovery rate: a practical and powerful approach to multiple testing. J R Stat Soc Ser B Stat Methodol. 1995:57:289-300.

17. $\operatorname{TaqMan}^{\oplus}$ Endogenous control assays to select an endogenous control for experimental studies (Publication C016806)) Life Technologies.

18. Edgar R, Domrachev M, Lash AE. Gene Expression Omnibus: NCBI gene expression and hybridization array data repository. Nucleic Acids Res. 2002;30:207-10.
19. Weiss A, McDonough D, Wertman B, Acakpo-Satchivi L, et al. Organization of human and mouse skeletal myosin heavy chain gene clusters is highly conserved. Proc Natl Acad Sci U S A. 1999;96:2958-63.

20. Chikuni K, Muroya S, Nakajima I. Absence of functional myosin heavy chain 2b isoform in equine skeletal muscles. Zoolog Sci. 2004;21:589-96.

21. Quiat D, Voelker KA, Pei J, Grishin NV, et al. Concerted regulation of myofiberspecific gene expression and muscle performance by the transcriptional repressor Sox6. Proc Natl Acad Sci U S A. 2011;108:10196-201.

22. Gunawan AM, Richert BT, Schinckel AP, Grant AL, et al. Ractopamine induces differential gene expression in porcine skeletal muscle. J Anim Sci. 2007:85:2115-24.

23. Smith SB, Garcia DK, Anderson DB. Elevation of a specific mRNA in longissimus muscle of steers fed ractopamine. J Anim Sci. 1989;67:3495-502.

24. Criswell DS, Powers SK, Herb RA. Clenbuterol-induced fiber type transition in the soleus of adult rats. Eur J Appl Physiol Occup Physiol. 1996;74:391-96.

25. Dodd SL, Powers SK, Vrabis IS, Criswell DS, et al. Effects of clenbuterol on contractile and biochemical properties of skeletal muscle. Med Sci Sports Exerc. 1996:28:669-76.

26. Zeman RJ, Ludemann R, Easton TG, Etlinger JD. Slow to fast alterations in skeletal muscle fibers caused by clenbuterol and beta2-receptor agonist. Am J Physiol. 1988;254:E726-32.

27. Eizema K, van der Burg M, Kiri A, Dingboom EG. Differential expression of equine myosin heavy-chain mRNA and protein isoforms in a limb muscle. Histocehm Cytochem. 2003:51:1207-16.

28. Serrano AL, Perez M, Lucia A, Chicharro JL, et al. Immunolabelling, histochemistry and in situ hybridization in human skeletal muscle fibers to detect myosin heavy chain expression art he protein and mRNA level. J Anat. 2001;199:329-37.

29. Smerdu V, Erzen I. Dynamic nature of fibre-type specific expression of myosin heavy chain transcripts in 14 different human skeletal muscles. J Musc Res Cell Motil. 2001;22:647-55.

30. Lefaucheur L, Ecolan P, Plantard L, Gueguen N. New insights into muscle fiber types in the pig. J Histochem Cytochem. 2002;50:719-30.

31. Muller-Newen G, Stoffel W. Mitochondrial 3-2trans-Enoyl-CoA isomerase. Purification, cloning, expression and mitochondrial import of the key enzyme of unsaturated fatty acid beta-oxidation. Biol Chem Hoppe Seyler. 1991;372:613-24.

32. Hulver MW, Befggren JR, Carper JM, Miyazaki M, et al. Elevated stearoyl-CoA desaturase-1 expression in skeletal muscle contributes to abnormal fatty acid partitioning in obese humans. Cell Metab. 2005;2:251-61.

33. Sato $S$, Nomura $S$, Kawano F, Tanihata J, et al. Effects of the $\beta_{2}$-agonist clenbuterol on $\beta_{1}$-and $\beta_{2}$-adrenoreceptor mRNA expressions of rat skeletal and left ventricle muscles. J Pharmacol Sci. 2008:107:393-400.

34. Abraham G, Brodde OE, Ungemach FR. Regulation of equine lymphocyte $\beta$-adrenoreceptors under the influence of clenbuterol and dexamethasone. Equine Vet J. 2002;34:587-93.

35. Sato $S$, Nomura $S$, Kawano F. Adaptive effects of the $\beta_{2}$-agonist clenbuterol on expression of $\beta_{2}$-adrenoreceptor mRNA in rat fast-twitch fiber rich muscles. J Physiol Sci. 2010;60:119-27.

\section{Submit your next manuscript to BioMed Central and we will help you at every step:}

- We accept pre-submission inquiries

- Our selector tool helps you to find the most relevant journal

- We provide round the clock customer support

- Convenient online submission

- Thorough peer review

- Inclusion in PubMed and all major indexing services

- Maximum visibility for your research

Submit your manuscript at www.biomedcentral.com/submit 